\title{
Surface-Induced Dissociation of Multiply Protonated Peptides
}

\author{
Ashley L. McCormack*, Jennifer L. Jones, and Vicki H. Wysocki \\ Department of Chemistry, Virginia Commonwealth University, Richmond, Virginia, USA
}

We report here surface-induced dissociation spectra of three multiply charged peptides: doubly protonated angiotensin I, doubly protonated renin substrate, and triply protonated melittin. For comparison, the collision-activated dissociation spectra of renin substrate and melittin are also presented. The spectra show that surface-induced dissociation provides structural information on multiply charged peptides at the picomole per microliter sample concentrations compatible with electrospray ionization. For multiply protonated angiotensin I, renin substrate, and melittin, surface collisions (100-165 eV) favor a limited number of fragmentation pathways, which are the same as those favored in collision-activated dissociation experiments. (J Am Soc Mass Spectrom 1992, 3, 859-862)

$\mathrm{I}$ n the case of singly protonated peptides produced by liquid secondary ion mass spectrometry (LSIMS), gas-phase collisional excitation of large peptides $(<3000 \mathrm{Da})$ produces sufficient fragmentation for structural analysis [1]. Extension to larger peptides is limited by losses in desorption and ionization efficiency and by the partitioning of a limited amount of internal energy to a large number of vibrational modes. Electrospray ionization (ESI) has gained considerable attention because it is an efficient means of generating multiply charged ions from large biomolecules, including proteins [2-6]. Although the fragmentation mechanisms for formation of multiply charged peptides have not been fully elucidated, low-energy gas-phase collisional activation of mass-selected multiply protonated peptides has been shown to provide structural information [3]. Collision-activated dissociation (CAD) of peptides between the ESI skimmer cone and capillary can provide an additional method for obtaining sequence information [7, 8]. Surface-induced dissociation (SID) is an alternative means of dissociating ions; several investigators have reported SID spectra of singly charged peptides produced by LSIMS [9-13]. We report here SID spectra of multiply charged peptides and compare the spectra with those obtained by CAD.

\section{Experimental}

The instruments used in this investigation were a simple, incxpensive dual quadrupole mass spectrome-

\footnotetext{
* Present address: University of Washington, GJ-10 4909 25th Avenue NE, Seattle, WA 98195.

Address reprint requests to Vicki $H$. Wysocki, Department of Chemistry, Virginia Commonwealth University, Richmond, VA 23284-2006.
}

ter specifically designed for ion/surface studies [14] and a triple quadrupole mass spectrometer (Finnigan TSQ70, San Jose, CA). Experimental details for the triple quadrupole mass spectrometer have been reported previously [15]. The SID instrument consisted of two Extrel (Pittsburgh, PA) quadrupoles ( $m / z$ range $0-4000 \mathrm{Da}$ ) arranged at $90^{\circ}$, with a surface positioned to intersect the ion optical path of each quadrupole. The angle of the incident beam was $50^{\circ}$ with respect to the surface normal. The surface used in this investigation was stainless steel, although alternative surfaces are being investigated [16]. Data were acquired and processed with a Teknivent/Vector Two data system (Maryland Heights, MO).

Electrospray ionization on the SID instrument was accomplished by using a modified version of the recently published electrospray designs of Chowdhury et al. [17] and Papac et al. [18]. The samples were dissolved in a 1:1 methanol:1\% acetic acid solution at final concentrations of $10-30 \mathrm{pmol} / \mu \mathrm{L}$. Samples were sprayed with a syringe pump through a syringe needle $(4-5 \mathrm{kV})$ toward a metal capillary $(170-200 \mathrm{~V})$ at a rate of $2 \mu \mathrm{L} / \mathrm{min}$. A heater wire in fiberglass sleeving was wrapped around the metal capillary to thermally desolvate the ions. The multiply protonated peptides were mass selected by $\mathrm{Q} 1$ and allowed to collide with the surface at a selected laboratory collision energy. The product ions were analyzed by Q2. The laboratory collision energy is determined by (1) the potential difference between the skimmer cone and the surface and (2) the charge state of the ion. For simplicity, the potential difference between the skimmer cone and surface will be listed as $\Delta V$; the kinetic energy of the collision is determined by multiplying $\Delta V$ by the charge state. Good quality SID spectra can be obtained 
by averaging data for a total sample spray time corresponding to $<500 \mathrm{pmol}$; this is higher than the low picomole levels (10-50 pmol) required for LSIMS/SID [19] and thus may reflect sample loss prior to Q1 rather than losses in the activation step.

\section{Results}

Surface-induced dissociation spectra are shown below for three peptides: doubly protonated angiotensin $\mathrm{I}_{r}$ doubly protonated renin substrate, and triply protonated melittin. For comparison, the CAD spectra of renin substrate and melittin are also presented. The peptides vary in average molecular mass from 1295.5 to 1758.0 to 2846.5 , respectively.

The SID spectrum obtained for doubly protonated angiotensin $\mathrm{I}$ is shown in Figure $1 \mathrm{~cm} / \mathrm{z}$ 648.7, [M + $2 \mathrm{H}]^{+}+, \Delta V=50$ ). Extensive fragmentation occurs upon SID and results in mainly singly charged product ions. The series of $b$-type ions detected allows the assignment of residues 3 to 6 . Dominant immonium ions from the tyrosine, histidine, and proline residues are also detected and are indicative of the high-energy deposition associated with SID. A systematic investigation [19] of the influence of molecular size and collision energy on the SID fragmentation of singly protonated peptides has shown that at a given collision energy the higher mass fragment ions are more prominant for larger peptides than for smaller peptides. However, low-mass immonium ions are generally the most abundant fragment ions in the spectra, unless very low collision energies are used (e.g., $10 \mathrm{eV})$.

The SID spectrum obtained for a larger doubly protonated ion, renin substrate, is shown in Figure 2a $\left(m / z\right.$ 880.0, $\left.[\mathbf{M}+2 \mathrm{H}]^{++} ; \Delta V=50\right)$. High-mass ions are of greater relative abundance for the compound of higher molecular weight (cf Figure 1 and Figure 2a).

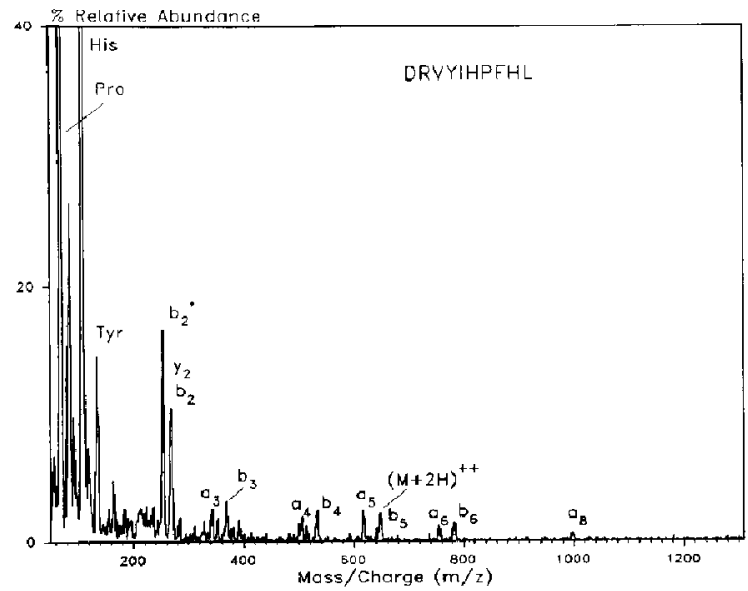

Figure 1. Surface-induced dissociation spectrum for the $[\mathrm{M}+$ $2 \mathrm{H}]^{++}$ion $(\mathrm{m} / \mathrm{z} 648.7)$ of angiotensin $\mathrm{I}$ at a collision energy of $100 \mathrm{eV}(\Delta V=50)$.
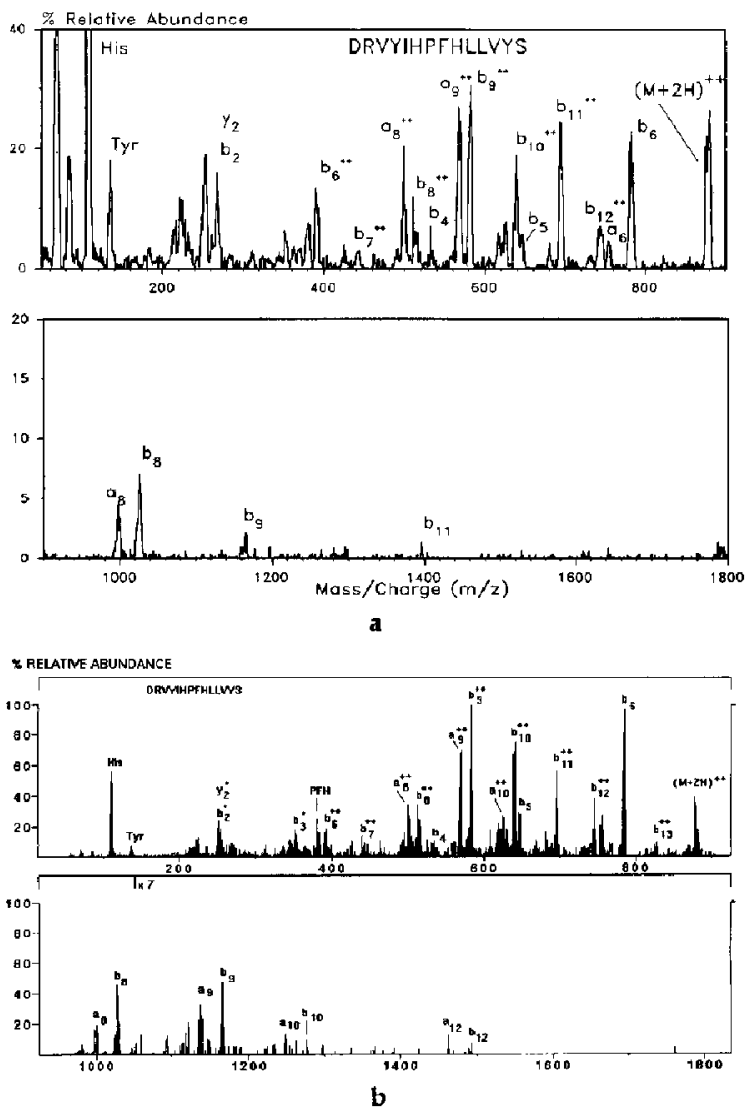

Figure 2. (a) Surface-induced dissociation spectrum for the [M $+2 \mathrm{H}]^{++}$ion $(m / z 880.0)$ of renin substrate at a collision energy of $100 \mathrm{eV}(\Delta V=50)$. (b) Collision-activated dissociation spectrum for the $[\mathrm{M}+2 \mathrm{H}]^{++}$ion $(\mathrm{m} / \mathrm{z} 880.0)$ of renin substrate at a collision energy of $60 \mathrm{eV}(\Delta V=30)$.

The series of $b$-type ions allow the assignment of residues $3-6$ and 9 and the series of doubly charged $b$-type ions allow the assignment of residues $7-12$. Several immonium ions are also detected. Few y-type ions are present in the spectrum, which is reasonable because the most basic amino acid is located near the $\mathrm{N}$-terminus of the peptide. For comparison, the CAD spectrum obtained at $\Delta V=30$ for the $[\mathrm{M}+2 \mathrm{H}]^{++}$ ion, $m / z 880.0$, generated from renin substrate is shown in Figure 2b. The CAD spectrum is remarkably similar to the SID spectrum. It exhibits a series of $b$-type ions, which allows the assignment of residues 3-6 and 9-10, and a series of doubly charged b-type ions, which allows the assignment of residues 7-13.

The SID spectrum for a triply protonated, 27-residue peptide, melittin, is shown in Figure $3 a(m / z$ 949.8, $[\mathrm{M}+3 \mathrm{H}]^{+++} ; \Delta V=55$ ). A series of $b$-type ions allows the assignment of residues $3-5$ and a series of doubly charged $y$-type ions allows the assignment of residues 5-9, 12, and 13. Again, low-mass ions are of greater relative abundance than high-mass ions. For 

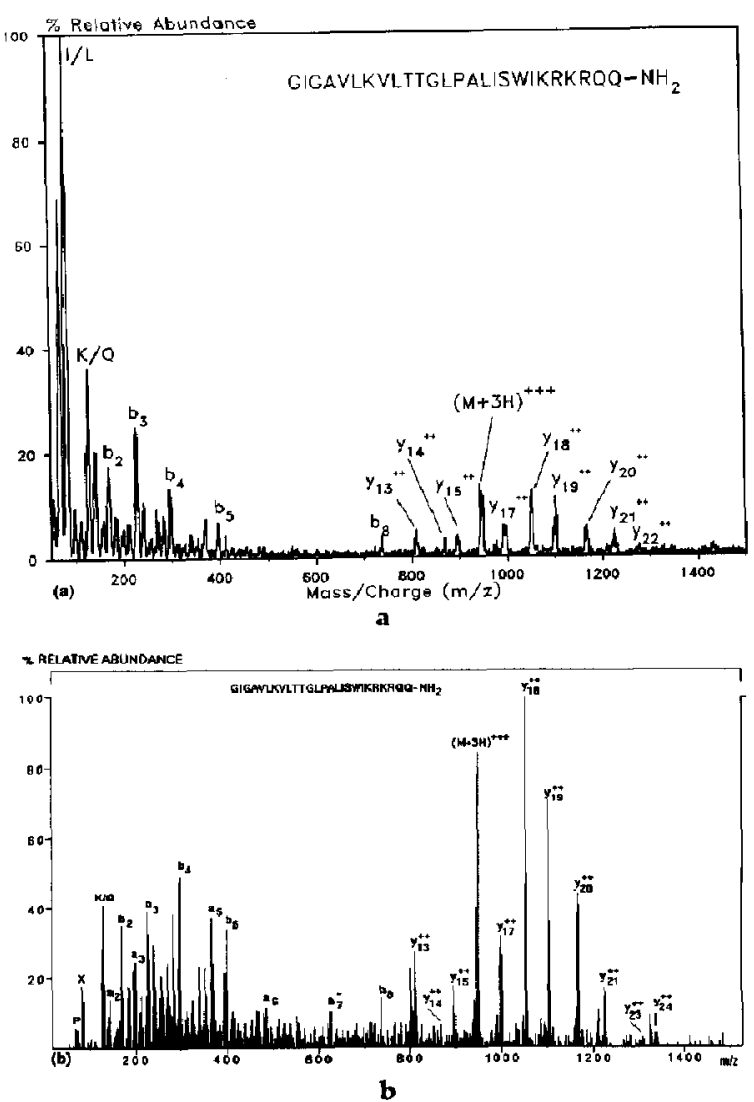

Figure 3. (a) Surface-induced dissociation spectrum for the [M $+3 \mathrm{H}]^{++}+$ion $(\mathrm{m} / z$ 949.8) of melittin at a collision energy of $165 \mathrm{eV} \Delta V=55$. (b) Collision-activated dissociation spectrum for the $[\mathrm{M}+3 \mathrm{H}]^{+++}$iun $(m / z$ 949.8) of melittin al a collision energy of $90 \mathrm{eV}(\Delta V=30)$.

comparison, the CAD spectrum obtained at $\Delta V=30$ for the $[\mathrm{M}+3 \mathrm{H}]^{+++}$ion, $m / z$ 949.8, generated from melittin, is shown in Figure 3b. Essentially the same ions are present as those detected in the SID spectrum. Interestingly, the two spectra of Figure 3 (165-eV SID and $90-\mathrm{eV}$ (AD) are very similar to the $565 \mathrm{eV}$ CAD spectrum reported by Barinaga and co-workers [20].

Experiments are in progress to determine the influence of the ionization technique, molecular size, collision energy, charge state, and type of surface on the information content of the spectra. For example, the ratio of $a: b$ ions increases with increasing collision energy for both singly and multiply protonated peptides, (2) the total scattered ion abundance increases if the stainless steel surface is replaced with a surface composed of perfluoro-terminated or amino-terminated alkanethiolate self-assembled monolayer films, and (3) at a given collision energy, ions produced by ESI fragment much less extensively than those produced by LSIMS. Conditions required to produce side-chain cleavage ions of type $d$ and $w$ [21] will also be deter- mined. Peaks corresponding to these ions are present in the SID spectra of singly charged ions produced by LSIMS [19], but are not present in the ESI/SID spectra of Figures 1-3.

\section{Conclusions}

The spectra reported here show that SID provides structural information on multiply protonated peptides at the picomole per microliter sample concentrations normally used with ESI of peptides. The similarity between SID and CAD spectra of multiply protonated peptides suggests that multiple sites of protonation within the peptide ion may serve to promote specific fragmentation pathways. That is, for any given multiply protonated peptide, there may be a number of kinetically favored fragmentation pathways that dominate the CAD or SID spectra, even though the average internal energy deposited is different. Overall, the results show that SID is at least as effective as CAD for the structural characterization of multiply protonated peptides.

\section{Acknowledgments}

We thank Kevin L. Schey and Damon I. Papac for assistance with the design and operation of the electrospray ionization source and Donald $\mathbf{F}$. Hunt for the use of the triple quadrupole mass spectrometer. This work was supported by the Society for Analytical Chemists of Pittsburgh, a Virginia Commonwealth University Grant-in-Aid, the Thomas $F$, and Kate Miller Jeffress Memorial Trust, and the Office of Naval Research.

\section{References}

1. Biemann, K. Biomed, Environ. Mass Spectrom. 1988, 16, 99-111.

2. Carr, S. A.; Hemling, M. E.; Bean, M. F.; Roberts, G. D. Anal. Chem. 1991, 63, 2802-2824.

3. Smith, R. D.; Loo, J. A.; Edmonds, C. G.; Barinaga, C. J.; Udseth, H. R. Anal. Chem. 1990, 62, 882-899.

4. Fenn, J. B.; Mann, M.; Meng, C. K.; Wong, S. F.; Whitehouse, C. M. Science 1989, 246, 64-71.

5. Mann, M. Organic Mass Spectrom. 1990, 25, 575-587.

6. Hamdan, M; Curcuruta, O. Int. J. Mass Spectrom. Ion Proc. 1991, 108, 93-113.

7. Loo, J. A.; Edmonds, C. G.; Udseth, H. R.; Smith, R. D. Anal. Chem. Acta 1990, 241, 167-173.

8. Katta, V.; Chowdhury, S. K,; Chait, B. T. Anal. Chem. 1991, $63,174-178$.

9. Cooks, R. G.; Amy, J. W.; Bier, M.E.; Schwark, J. C.; Schey, K. L. Adv. Mass Spectrom. 1989, 11, 33-52.

10. Bier, M. E.; Schwartz, J. C.; Schey, K. L.; Cooks, R. G. Int. J. Mass Spectrom. Ion Proc. 1990, 103, 1-19.

11. Aberth, W. Anal. Chem. 1990, 62, 609-611.

12. Williams, E. R.; Henry, K. D.; McLafferty, F. W.; Schabanowitz, J.; Hunt, D. F. J. Am. Soc. Mass Spectrom. 1990, 1, 413-416.

13. Cole, R. B.; LeMeilour; Tabet, J.-C. Annl. Chem. 1992, 64, 365-370.

14. Wysocki, V. H.; Ding, J.-M.; Jones, J. L.; Callahan, J. H.; King, F. L. J. Am. Soc. Mass Spectrom. 1992, 3, 27-32. 
15. (a) Hunt, D. F.; Shabanowitz, J.; Martino, P. A.; McCormack, A. L.; Michel, H.; Alexander, J. E.; Sherman, N. Current Research in Protein Chemistry: Techniques, Structure and Function; Academic Press: New York; 1991; Pp. 441-454. (b) Payne, D. M.; Rossomando, A. J.; Martino, P. A.; Erikson, A. K.; Her, J. H.; Shabanowitz, J.; Hunt, D. F.; Weber, M. J.; Sturgill, T. W. EMBO J. 1991, 10, 885-892.

16. (a) Wysocki, V. H.; Jones, J. L.; Ding, J.-M. J. Am. Chem. Soc. 1991, 113, 8969-8970. (b) Somogyi, A.; Kane, T. E.; Ding, J.-M.; Wysocki, V. H., submitted.
17. Chowdhury, S. K.; Katta, V.; Chait, B. T. Rapid Commz. Mass Spectrom. 1990, 4, 81-87.

18. Papac, D. I.; Schey, K. L.; Knapp, D. R. Anal. Chem. 1991, 63, $1658-1660$

19. McCormack, A. L.; Somogyi, A.; Dongre, A. R.; Wysocki, V. H., manuscript in preparation.

20. Barinaga, C. J.; Edmonds, C. G.; Udseth, H. R.; Smith, R. D. Rapid Commun. Mass Spectrom. 1989, 3, 160-164.

21. Johnson, R. S.; Martin, S. A.; Biemann, K. Int. J. Mass Spectrom. Ion Proc. 1988, 86, 137-154. 